\title{
A CONTRIBUIÇÃO DE UM DICIONÁRIO HISTÓRICO: O DICIONÁRIO HISTÓRICO DO PORTUGUÊS DO BRASIL
}

\author{
Clotilde de Almeida Azevedo Murakawa*
}

\begin{abstract}
This article presents the theoretical and methodological road used to construct the Historical Dictionary of Brazilian Portuguese in the XVI, XVII and XVIII centuries (sponsored by $\mathrm{CNP} q$ ). Starting with some examples and models of historical and diachronic dictionaries we set the model that structures the Dictionary; it has the purpose of assembling in a single book the Portuguese language lexicon responsible for the construction of the Portuguese language in Brazil. Our reference basis is a data bank with many sorts of sources existing along the three centuries of the Brazilian colonial history. This data bank provides the nomenclature of the historical dictionary and allows the construction of the lexicographical definition through its lexical context that is followed by consecrated examples. This article also presents the contributions of the dictionary to future studies of the Brazilian Portuguese.
\end{abstract}

Key-words: historical dictionary, lexicography, corpus linguistics, definition, lexicographical paper, Portuguese language history, Brazilian colonial history.

\section{O DICIONÁRIO HISTÓRICO}

A definição de dicionário histórico, de acordo com a moderna lexicografia de linha francesa e espanhola, não é unânime. Buscando ordenar algumas definições de linguistas sobre o tema, pode-se iniciar esta reflexão com os franceses Dubois \& Dubois (1971) que, ao estabelecerem a relação entre história e dicionário, afirmam que ao se fazer a descrição histórica de uma língua, há a necessidade de se empregar uma metalíngua: faz-se uma descrição sincrônica de uma evolução diacrônica. Para os autores, os verdadeiros dicionários históricos são aqueles que definem um estado de língua correspondendo a um funcionamento historicamente definido, e a metalíngua empregada só pode ser feita com palavras da língua atual, ou seja, da época em que o dicionário está sendo construído. Dubois \& Dubois afirmam ainda que para cada período de língua não só os sentidos novos devem ser buscados, mas também os antigos que existem ao lado dos novos. O conteúdo semântico de cada palavra sofre os efeitos de seu percurso no tempo e no espaço.

Segundo Haensch (1982), a finalidade do dicionário histórico é registrar a evolução que as palavras sofrem ao longo do tempo, utilizando os textos com suas datas correspondentes, indicando grafias diferentes e a variação semântica e morfológica encontradas. O dicionário histórico é, para o autor de La tipologia de las obras lexicográficas, capítulo que integra a obra La Lexicografia (1982), uma obra documentada, ou seja, a contextualização da palavra-entrada e sua datação são elementos importantes. Tal tipo de dicionário histórico difere do etimológico que busca registrar a origem da palavra e de sua suposta pré-história.

Com uma posição bastante diversa dos linguistas anteriormente mencionados, Rey-Debove afirma que o dicionário histórico "é aberrante, mas útil" (1984, p. 67). Este tipo de dicionário, para a lexicógrafa francesa, não descreve a língua real, mas reúne palavras de todas as épocas e

* Docente do Programa de Pós-graduação em Linguística e Língua Portuguesa, UNESP - campus de Araraquara/ CNPq. 
que não funcionam sistematicamente. Talvez, por isso, o considere aberrante. Mas justifica sua posição considerando sua utilidade, pois o vocabulário passivo das pessoas cultas, pode, por um lado, recuar muito no tempo, e por outro, deve registrar as palavras desconhecidas, pois muitas vezes, as palavras mais antigas são as desconhecidas de uma determinada sociedade.

Usando a terminologia de dicionários diacrônicos, Porto-Dapena (2002), os subdivide em etimológicos e históricos. Para o autor, o dicionário histórico deve se ocupar da história das palavras até o momento mais presente, atual; já o etimológico deve ter sua atenção voltada para a origem das palavras, ou como diz Porto-Dapena (2002, p. 51), "para a sua pré-história".

Para os autores de El diccionario y otros productos lexicográficos (2003, p. 50), Campos Souto e Perez Pascual, os dicionários históricos são os que documentam as mudanças, que ao longo do tempo as palavras sofrem, acompanhadas de uma vasta documentação testemunhal; são eles dicionários de língua construídos com um método sincrônico.

Foi pensando na organização e construção de um dicionário histórico do português do Brasil que Maria Tereza C. Biderman traçou as diretrizes de um dicionário histórico que registrasse a língua portuguesa que teria servido de base para o a constituição do acervo lexical do português do Brasil. O Projeto Dicionário Histórico do Português do Brasil - séculos XVI, XVII e XVIII foi apresentado, em 2005, ao Programa Institutos do Milênio do CNPq e teve, no mesmo ano, sua aprovação confirmada.

Das definições de dicionário histórico anteriormente apresentadas e que manifestam o pensamento de alguns lexicólogos/lexicógrafos franceses e espanhóis, num período de aproximadamente 50 anos entre eles, pode-se chegar a uma definição precisa do que seja o Dicionário Histórico do Português do Brasil, ou seja, o DHPB, como é, atualmente, mais conhecido.

O DHPB é, portanto, um dicionário histórico que está sendo construído sobre um conjunto de documentos dos séculos XVI, XVII e XVIII que testemunham o período da história colonial do Brasil; além das mudanças semânticas, objeto de atenção do DHPB, registra também as variantes gráficas e morfológicas da palavra-entrada, acompanhadas dos contextos onde tais variantes estão inseridas; é um dicionário que registra a datação das unidades lexicais no conjunto dos documentos que integram o banco de dados, onde se assenta a estrutura do DHPB.

Neste artigo, enquanto vai-se apresentando a construção de sua macro e microestrutura, vão sendo destacadas, paralelamente, as contribuições de ambas as estruturas para o estudo da língua portuguesa num período de tempo em que se foi formando a identidade brasileira em termos de língua e de nação. O nome histórico como qualificativo do dicionário não é somente porque a obra de referência registra as mudanças semânticas, gráficas, fonéticas ou morfológicas que as palavras sofrem num período de tempo, mas também porque, ao ser construído sobre uma base informatizada formada de documentos dos séculos XVI, XVII e XVIII, resgata a história da língua e a história política, administrativa, econômica, cultural e religiosa do Brasil Colônia. Toda a organização do artigo lexicográfico do DHPB procura não perder de vista o cenário histórico maior, e por esta razão, este artigo está exaustivamente documentado com contextos das diferentes épocas.

\section{A MACROESTRUTURA DO DHPB}

A macroestrutura de todo e qualquer dicionário está constituída de um número determinado de lemas ou entradas, em ordem alfabética, e de subentradas. A soma de todas as entradas forma a macroestrutura do dicionário, também denominada nomenclatura. De acordo com o tipo do dicionário faz-se a seleção das unidades lexicais que vão formar a nomenclatura.

Para a seleção da nomenclatura do DHPB, foi construída uma base textual como corpus de referência, a partir de um vasto conjunto de documentos de todo tipo e gênero, situados no período compreendido entre 1500 e 1808, duas datas de suma importância para a história do Brasil. A data de 1500, o descobrimento, com a Carta de Pero Vaz de Caminha, e a de 1808, 
quando da vinda da família real portuguesa, mudando o Brasil de colônia para Vice-Reino. Foi neste período de tempo de 3 séculos que se buscou o acervo documental para o banco de dados. Pôde-se, assim, reunir dos três séculos uma grande variedade de documentos de todo tipo e gênero, como: obras dos missionários viajantes, na sua maioria jesuítas que vieram em missão catequética e no Brasil se fixaram; diários de navegação, como o de Pero Lopes de Sousa, irmão de Martim Afonso de Sousa; cartas de sesmarias; roteiros descritivos da flora e fauna brasileiras; descrições geográficas; cartas e sermões do Pe.Vieira, pregados aqui no Brasil e de outros oradores sacros, que para aqui vieram e que tiveram sua correspondência reunida em obras esparsas; obras e documentos que tratam do Estado do Grão Pará, durante a era pombalina; cartas comerciais trocadas entre comerciantes da colônia com outros de Portugal; obras sobre a nobiliarquia paulistana; atos de câmaras municipais; anais de câmaras de diversos municípios brasileiros; documentos cartoriais; autos de devassas feitos durante a Inconfidência Mineira; processos; inventários; testamentos; alvarás; posturas; bandos; atos de doações de terras, casas e terrenos; cartas de ofício; patentes; cartas dos governadores gerais; provisões; documentos forenses; estatutos de sociedades; constituições dos bispados do Brasil; regimentos militares; obras sobre medicina, farmácia, agricultura, mineração, além da produção literária do barroco e arcadismo no período.

Denominado de Banco I ao primeiro que foi montado, ele registra 7.492 .472 ocorrências. Paralelamente a este banco, foi construído o Banco II que veio para completar o primeiro, pois este ficou, até certo ponto, desfalcado de documentos dos séculos XVI e XVII.

Para se construir o banco que permitisse aos redatores extraírem as unidades lexicais para a elaboração do artigo lexicográfico, vários procedimentos precisam ser seguidos: 1) seleção dos textos a serem escaneados; 2) escaneamento dos textos e edição das imagens; 3) organização das pastas onde cada pasta corresponde a uma obra; 4) a partir da leitura ótica (Optical character recognition - OCR) e correção pelo programa $A B B Y Y$ Fine Reader, faz-se a transferência das imagens para textos (TIFF > DOC); 5) inclusão da ficha catalográfica nos textos já corrigidos; 6) conversão para arquivos texto (TXT); 7) marcação XML (eXtensible Makeup Language); 8) inserção dos textos no programa Philologic ${ }^{1}$. Cada banco tem arquivada a imagem dos textos no original e isto permite que, em caso de dúvida, sempre se volte a ele. Através de um motor de busca, todo o banco pode ser consultado.

Para cada texto inserido no banco, foi elaborada uma ficha catalográfica onde estão registrados os seguintes dados: autor do texto, título do texto, data em que o autor o produziu, amostra, se integral ou parcial, título da obra, editor ou organizador, quando for o caso, editora, local e data da edição, e volume. Completam a ficha: informação biográfica sobre o autor, descrição da obra, localização da obra, ou seja, em que acervo, biblioteca no Brasil ou exterior o documento foi encontrado.

O DHPB se encontra em sua fase de construção e é partir de um banco de dados de 10 milhões de ocorrências que se pretende chegar a uma obra de referência com 10 mil verbetes. A sede do projeto do Dicionário Histórico é o Laboratório de Lexicografia na Faculdade de Ciências e Letras da UNESP de Araraquara.

A construção deste corpus de referência constituiu uma das grandes contribuições do Projeto do DHPB, pois no Brasil, não há ainda obra lexicográfica sobre o léxico do português nos primeiros tempos de sua formação, elaborada sobre base informatizada de documentos produzidos nos séculos XVI, XVII, XVIII e princípios do XIX.

Ainda no que se refere à macroestrutura do DHPB, destaca-se o procedimento adotado com relação a palavras homônimas - homógrafas e homófonas. Muito embora para inserção de homônimos em entradas separadas haja alguns critérios estabelecidos pela prática lexicográfica, para o DHPB os critérios etimológico ou diacrônico, gramatical e semântico foram empregados. Exemplifica-se, a seguir, o emprego de cada um dos critérios, com seleção de contextos

\footnotetext{
${ }^{1}$ O programa Philologic é um sistema de processamento de corpus criado na Universidade de Chicago.
} 
extraídos do banco de dados².

a) critério etimológico ou diacrônico registrando em entradas separadas as palavras de origem diferente:

$\operatorname{bote}^{1}$ s.m.

variante: botte.

Pequeno barco sem cobertura, que anda a remo ou à vela e que serve para o transporte de gente e também de carga.

[...] no outro Botte se embarcou o Ten.te Josê de S. Payo Lansarote, o Tenente Fran.co Xavier Dorta, em huma Canoa; em outra o Sargento Pedro de Figueiredo de Vasconcelos; [...]. Pe JESUITA RAYMUNDO LAYNES (1991) [1759], "NOTICIAS PERTENCENTES A COMMUNICAÇAÕ DO MATTO GROSSO COM O ESTADO DO MARANHAÕ. ANNO D' 1748" - EXCERTOS DO ARQUIVO DO MORGADO DE MATEUS / III - DIÁRIO EXATO DO QUE SE TEM PASSADO NESTAS FRONTEIRAS DE MATO GROSSO E SANTA CRUZ DE LA SIERRA. 1759-1764. / DIARIO EXACTO DO QUE SE TEM PASSADO NESTAS FRONTEIRAS DE MATTO GROÇO, E S. CRUZ DE LA SIERRA DESDE O ANNO DE 1759. TÊ O PRINCIPIO DO ANNO D' 1764. [A00_1244 p. 103].

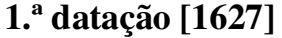

[...] os quaes por irem muitos doentes das gengivas, a que chamão mal de Loanda, o lançarão em hum pequeno bote com quatro marinheiros Portuguezes na Iliceira, pera que lhe fossem buscar alguns limões, [...]. FREI VICENTE DE SALVADOR (1888) [1627], LIVRO QUINTO - DA HISTORIA DO BRASIL DO TEMPO QUE O GOVERNOU GASPAR DE SOUZA ATHÉ A VINDA DO GOVERNADOR DIOGO LUIZ DE OLIVEIRA - CAPITULO VIGESIMO - DE COMO ANTONIO BARREIROS, FILHO DO PROVEDOR MÓR DA FAZENDA, FOI POR PROVISÃO DO GOVERNADOR GERAL DIOGO DE MENDONÇA FURTADO GOVERNAR O MARANHÃO, BENTO MACIEL O GRAM-PARÁ, E O CAPITÃO LUIZ ARANHA A DESCOBRIL-O PELO CABO DO NORTE POR MANDADO DE SUA MAGESTADE [A00_2090 p. 204].

$\operatorname{bote}^{2}$ s.m.

variante: bóte.

1. Movimento que a cobra faz para atacar e morder.

[...] a cobra levantava o collo, armava o bote, o teyú no mesmo instante lho desvanecia com o açoite da cauda; ella repetia a diligencia, querendo empregar o morso, elle com incrivel ligeireza se desviava, [...]. FRANCISCO ANTÔNIO DE SAMPAIO (1971) [1782], TEYÚ [A00_1769 p. 51].

2. Golpe de lança, espada,florete, atirando de ponta para diante.

[...] se porem o caçador he experimentado e que, dando o tiro ou bóte, sóbe a alguma arvore geitoza, de sima della pode com huma lança ou chuço malar quantos porcos quizer, tendo a certeza de que elles se não apartão em quanto ouvem chiar os companheiros. LUIZ DOS SANTOS VILHENA (1921) [1801], CARTA VIGESIMA: [A00_0846 p. 718].

\section{1. a datação [1782]}

\footnotetext{
${ }^{2}$ Todos os contextos que exemplificam este artigo foram extraídos do banco de dados do DHPB, mantendo a informação bibliográfica e a numeração dos arquivos; alterou-se, apenas, a fonte e tipo de letra para adequar às normas desta revista.
} 
Não corre a investir, mas arma o bote, tocando o cascavel com incrivel movimento vibrativo da cauda, espera sem receio, morde sem temor. FRANCISCO ANTÔNIO DE SAMPAIO (1971) [1782], CASCAVEL (COBRA DE) [A00_1770 p. 53].

b) critério gramatical, registrando separadamente unidades que nos contextos têm função diferente como em

ermo $^{1}$ s.m.

Lugar longínquo, desabitado, deserto.

Tu tambem, innocente habitante d'estes ermos, o lerás; e se o Céo me escula, teus dias serão longos, pois tanto te agradeci teu canto e tua visita. JOSÉ VIEIRA COUTO (1842) [1801], ITINERARIO ABAITÉ ACIMA AO RIBEIRÃO DA GALENA [A00_2359 p. 71]. ermo $^{2}$ adj.

Diz-se de lugar longínquo, desabitado, deserto.

Isto julgavão aquelles padres dos lugares ermos: mas quanto se devem considerar mais funestos á virtude os que tendo annexos os mesmos perigos da solidão, ajuntão ainda todas os estimulos, e facilidades, que costumão influir para o complemento da paixão brutal [...]. DOM FREI CAETANO DA ANNUNCIAÇÃO BRANDÃO (1991.) [1788], REFLEXÕES FEITAS PELO PRELADO NA VOLTA DA QUARTA VISITA [G00_0022 p. 158].

\section{$1^{\text {a }}$. datação [1638]}

Tinha andado tantos dias por aquelle deserto despovoado e ermo; e não é muito que a morte que temia cortezão, a desafiasse anacoreta. PADRE ANTONIO VIEIRA (1951) [1638], SERMÃO DA SANTA CRUZ [A00_0927 p. 23].

c) critério semântico, registrando as unidades cuja polissemia levou a significados distantes, permitindo que sejam consideradas unidades separadas:

beijo $^{1}$ s.m.

Ósculo; toque com os lábios em uma pessoa ou em qualquer objeto por mostra de amor, respeito ou religião.

Beije Glaura estas flores, E os encontrados beijos Dêm novo e puro ardor a meus desejos. MANOEL INÁCIO DA SILVA ALVARENGA (2003) [1799], V - "FOLHA POR FOLHA, E CHEIRO DE TERNURA" [A00_1187 p. 156].

\section{1.a datação [1792]}

Pego em seus dedos nevados, e querendo dar-lhe um beijo, cobriu-se todo de pejo e fugiu-me com a mão. TOMÁS ANTÓNIO GONZAGA (1961) [1792], 02. PINTAM, MARÍLIA, OS POETAS [A00_1266 p. 6].

beijo $^{2}$ s.m.

Flor natural da China, de cores variadas e de pouco cheiro.

Beijos - São flores de pouco cheiro, vistozas com cores mto vivas: há brancos, encarnados, e roxos: são arvores do tamanho das do Mangericão: hé nal da China, d'onde foi transplantada pa estas Regioens. ANÔNIMO (MUITO PROVAVELMENTE JOSEPH BARBOSA DE SÁA) (1999) [1765], [I]. NOTICIA DAS FLORES MAIS NOTAVEIS E CONHECIDAS Q, HÁ NO BRAZIL: COM A DENOMINAÇÃO DE OUTRAS MUITAS, Q' HÁ NOS MATOS, CAMPOS, E SERRADOS [A00_2208 p. 11]. (1.a datação) 
Os lexicógrafos de língua portuguesa ora privilegiam um, ora outro critério. Não há unanimidade sobre o tema. Sobre isso basta um olhar rápido sobre a Lexicografia portuguesa de setecentos e vai se encontrar no Vocabulário Portuguez e Latino (1712-1728) do Pe. Raphael Bluteua (1638-1734) um único procedimento, ou seja, Bluteau registra numa só entrada todos os valores semânticos do lema, não levando em consideração a classe gramatical, o étimo ou significado (MURAKAWA, 2005). Algumas décadas mais tarde, o Diccionario da Língua Portugueza de Antonio de Morais Silva (1755-1824), em suas duas primeiras edições de 1789 e 1813, toma o critério gramatical para separar as palavras homônimas (MURAKAWA, 2007).

Neste aspecto, o DHPB traz sua contribuição ao empregar os 3 critérios, principalmente, na utilização do critério gramatical e do semântico. Com relação ao gramatical, registra as possibilidades que o lema pode ter nos diferentes contextos, ora como substantivo, ora como adjetivo, evidenciando os valores polissêmicos do lema numa e outra classe gramatical. Veja-se abaixo o caso do verbete grego:

grego ${ }^{1}$ adj.

1. Pertencente ou relativo à Grécia.

Outro cometa annunciou a perda de Constantinopla, e lamentavel ruina do Imperio Grego. FR. DOMINGOS DE LORETO COUTO (1904) [1757], LIVRO OUTAVO - PERNAMBUCO CONSTANTE, VALEROSO, E FIEL NAS CALAMIDADES [A00_0825 p. 180].

2. Relativo à língua usada na Grécia.

Entre os primeiros Francezes, que vierão ao Rio de Janeiro em companhia de Nicoláu Villaganhon [...] vinha hum hereje calvinista chamado João Bouller, o qual fugio pera a Capitania de S. Vicente, onde os Portuguezes o receberão cuidando ser Catholico, e como tal o admittião em suas conversações, por elle ser tambem na sua eloquente, e universal na lingoa Hespanhola, Latina, Grega, e saber alguns principios da Hebréa [...]. FREI VICENTE DE SALVADOR (1888) [1627], LIVRO TERCEIRO - DA HISTORIA DO BRASIL DO TEMPO QUE O GOVERNOU THOMÉ DE SOUZA ATHÉ A VINDA DO GOVERNADOR MANOEL TELLES BARRETO - CAPITULO DECIMO SEGUNDO - DE COMO O GOVERNADOR MEN DE SÁ TORNOU AO RIO DE JANEIRO, E FUNDOU NELLE A CIDADE DE S. SEBASTIÃO, E DO MAIS QUE LÁ FEZ ATHE TORNAR Á BAHIA [A00_2022 p. 80].

3. Relativo à religião ortodoxa praticada na Grécia.

Viam-se pelas barreiras de Barcelos chorando algumas índias e mamelucas, e faziam chorar a quem pensasse na grande miséria em que vive esta gente tôda, fazendo um jejum que passa de magno, ou abstinência de carne, a ser a xerofagia da Igreja Grega, não tendo mais que beiju e pimentas para comer. ANTÔNIO PIRES DA SILVA PONTES (1964) [1781], III DOCUMENTOS - 5. DIÁRIO HISTÓRICO E FÍSICO DA VIAGEM DOS OFICIAIS DA DEMARCAÇÃO QUE PARTIRAM DO QUARTEL GENERAL DE BARCELOS PARA A CAPITAL DE VILA BELA DA CAPITANIA DE MATO GROSSO, EM 1 DE SETEMBRO DE 1781. POR ANTÔNIO PIRES DA SILVA PONTES. (COLEÇÃO MARCOS DE MENDONÇA, DE DOCUMENTOS) [A00_1138 p. 344].

4. Enigmático, ininteligível.

Alem disto, ordenou em casa que ouvesse cada dia huma hora de lição da lingoa brasilica, que quá chamamos grego; e elle hé o mestre dela pola saber entender e explicar suas regras milhor que todos, posto que sejão muy boas lingoas. P. RUI PEREIRA (1956) [1560], CARTA DO Pe. RUI PEREIRA AOS PADRES E IR. DE PORTUGAL, [BAÍA] I5 DE SETEMBRO 1560 [A00_0045 p. 306].

grego $\mathbf{2}^{2}$ s.m. 
Aquele que é habitante ou natural da Grécia.

A ambição levou os Persas contra os Babilonios; aos Gregos contra os Persas; aos Romanos contra os Gregos [...]. FREI DOMINGOS DE LORETO COUTO (1904) [1757], LIVRO SEGUNDO - PERNAMBUCO VENCIDO, E GLORIOSAMENTE RESTAURADO / CAP. IV-TRATA DA CONQUISTA DE PERNAMBUCO PELOS OLANDEZES. N. 20. [A00_0623 p. 90].

\section{$1^{\text {a }}$. datação [1560]}

[...] ho dito monsjor de boles gabaua de deuota a çea que se fazia no Rio de Janeiro comtando dela que nela excomungão / a mujtos gregos de pesoas amtre as quais excomungão hos sacrilegios que ele diz que entendem per os papistas [...]. JOÃO DE BOLÉS (1904) [1560], PROCESSO DE JOÃO DE BOLÉS E JUSTIFICAÇÃO REQUERIDA PELO MESMO (1560 1564) [A00_0827 p. 228].

Nos contextos acima, fica evidente que a polissemia é maior no adjetivo; já a datação mais antiga, no conjunto dos documentos do banco, está no substantivo.

O critério semântico separa as unidades lexicais cuja relação semântica está tão distante que não permite estabelecer uma relação de sentido entre os lemas. Registra-se abaixo o contexto onde se encontra a entrada compacto:

compacto $^{1}$ adj.

variante: compato.

Que tem os elementos, as unidades ou os segmentos de composição firmemente unidos entre si. Hé a jerema huma arvore de medeana altura; o seo tronco de huma substancia compata, e dura, coberto de huma casca alguma couza groça, e toda espinhoza [...]. FRANCISCO ANTÔNIO DE SAMPAIO (1971) [1782], JERÉMA [A00_1673 p. 61].

\section{$1^{a}$. datação [1711]}

E eftando defta forte, chama-fe Mel em ponto, groflo fufficientemente, \& compacto, \& jà difpofto para paffar á quarta Tacha, que chamaõ Tacha de bater [...]. ANDRÉ JOÃO ANTONIL (1711) [1711], LIVRO II - CAPITVLO I - DA EICOLHA DA TERRA PARA PLANTAR CANNAS DE AIIUCAR, \& PARA OS MANTIMENTOS NECEIIARIOS, \& PROVIMENTO DO ENGENHO [A00_2577 p. 71].

$\operatorname{compacto}^{2}$ s.m.

Pacto, contrato mutuamente obrigatório entre contratantes.

[...] como já outra vez não defendeu, nem sei se estas nossas deprecações, posto que tão repetidas e continuadas, acharão accesso a vosso compacto divino, [...]. PADRE ANTONIO VIEIRA (1951) [1640], SERMÃO PELO BOM SUCCESSO DAS ARMAS DE PORTUGAL CONTRA AS DE HOLLANDA [A00_1051 p. 318]. (19atação)

Os contextos acima documentam que o significado de compacto ${ }^{2}$ no excerto do Pe. Antonio Vieira (1608-1697) é do século XVII já o de André João Antonil (1649-1716), do século XVIII, mostrando, que entre as duas entradas há uma relação de significado, mas bastante distante, permitindo o registro em entradas separadas.

Segundo Castillo Carballo (2003), é ainda na macroestrutura de um dicionário que se deve tratar dos lemas de especialidade. No que diz respeito aos lemas de linguagens especiais, observa-se que o banco de dados do DHPB registra unidades lexicais que poderiam ser consideradas "termos", segundo critérios terminológicos; entretanto, não se adotou o critério de marca de especialidade, devido às dificuldades que os contextos apresentam, não permitindo uma marcação exata dada a complexidade de cada contexto. 
O banco de dados do DHPB tem, em seu conjunto, inúmeras obras sobre Medicina, Farmácia, nas quais as propriedades e virtudes de algumas plantas são evidenciadas. Tais textos tratam com objetividade das doenças e suas possibilidades de tratamento. Entretanto, os contextos não permitem ao redator colocar nos verbetes alguma marca de especialidade. Registra-se abaixo o verbete antimônio:

antimônio $s . m$.

variante: antimonio.

Metal frágil, pesado, de cor esbranquiçada, brilhante, composto de estrias sobrepostas e pegadas umas as outras.

Principiou a povoar-se no ano de 1728, quando se descobriu o ouro [no] mesmo morrode que tomou o nome e juntamente de um olho d'água que nele nasce quente em todas as estações do ano, a qual, dizem os mestres da medicina, passa por minas de antimônio e que é boa para várias enfermidades. CAETANO DA COSTA MATOSO/ JOSÉ DE LEMOS GOMES (1999) [1749], 12 - [INFORMAÇÃO DAS ANTIGUIDADES DA FREGUESIA DE CATAS ALTAS] [A00_0969 p. 267].

\section{Expressões sintagmáticas}

Antimônio diaforético

Produto químico bastante empregado para abrir o apetite e os poros para facilitar as secreções. Diagridio fulfurado dez oytavas, antimonio diaforetico feis oytavas, cremor tartari duas oytavas, e meya , mifture-fe, e fe façaõ pós: dofes, he de meya oytava até dous efcropulos: virtudes. LUIS GOMES FERREIRA (1735) [1735], DA MISCELLANIA DE VARIOS REMEDIOS, AIIM EXPERIMENTADOS, E INVENTADOS PELO AUTOR, COMO EICOLHIDOS DE VARIOS PARA DIVERTAS ENFERMIDADES. [B00_0031 p. 182].

Antimônio tartarizado

Tártaro formado de antimônio e potassa.

Tem tambem a differença, muitas vezes vantajosa, do Antimonio tartarisado, ou Tartaro emetico, em nunca se fazer taõ cathartica; este talvez por salino e soluvel nos liquidos, que encontra no estomago, precipita-se sempre em grande parte, e muitas vezes todo, e por isso naõ so existem sempre evacuações alvinas, depois de fazer vomitar [...]. BERNARDINO ANTONIO GOMES (1801) [1801], DAS VIRTUDES DA IPECAC [A00_1336 p. 19].

ver: tártaro; potassa.

A marca terminológica só aparece na definição quando o "termo" está presente no banco de dados, e através de remissiva, pode ser registrada a sua definição. É o que ocorre nos contextos acima, onde potassa e tártaro estão no banco.

A única marca utilizada no DHPB é a marca de difusão semântica, isto é, o sentido figurado que a entrada adquire no contexto, mantendo sob o rótulo figurado ( $f i g$.) tanto a metáfora quanto à metonímia. Na seção seguinte deste artigo, será o assunto novamente abordado.

\section{A MICROESTRUTURA DO DHPB}

Todo o artigo lexicográfico ou verbete do DHPB é construído a partir dos contextos do corpus. 
Denomina-se microestrutura o artigo lexicográfico, unidade mínima que dá sustentação ao dicionário. $\mathrm{O}$ centro do verbete é a definição que vem realçada pela palavra-entrada, registrada geralmente em negrito e seguida da classe gramatical.

Como o DHPB é uma obra que tem por objetivo reunir o acervo lexical do período colonial do português no Brasil, sentiu-se a necessidade da construção de um modelo de verbete que realçasse aspectos desse acervo representativo de um período histórico. Desta forma, o modelo de verbete reúne algumas peculiaridades linguísticas e históricas que poderão, num futuro, ser objeto de estudo de linguistas e historiadores.

Todas as entradas do DHPB são grafadas de acordo com o Vocabulário Ortográfico da Língua Portuguesa (2009) a fim de facilitar ao a consulta ao corpo do dicionário.

Tradicionalmente, a prática lexicográfica orienta registrar logo depois da classe gramatical, a definição ou definições da entrada. No caso do DHPB, procedeu-se diferente. Registra-se após a classe gramatical, todas as variantes que o lema possa ter registrado no banco de dados. Este tipo de registro é obtido através de um motor de busca do sistema Philologic; o motor denominado busca por similaridades, auxilia o redator a localizar todas as possibilidades que o lema possa ter, quer do ponto de vista ortográfico, quer morfológico nos mais diversos contextos. Muitas vezes, há a necessidade de se criar algumas variantes, dentro dos parâmetros possíveis da língua portuguesa para se obter outras variantes. Algumas entradas apresentam apenas uma variante, outras duas ou mais e outras, 12 ou 16 possibilidades. Em desafogo temse: dezafogo, desafôgo, dezafôgo. Em diminuição, tem-se: diminuiçaõ, demenuição, deminuição, demenuiçaõ, deminuiçã̃, diminuiçam, deminuisão, demenuisão, deminuiçam, deminuiçaó, demanuisam.

Todas as variantes encontradas são documentadas, ou seja, estão em contextos onde autor, título da obra e datação e página do documento estão registrados.

O destaque dado no DHPB para as variantes permite aos pesquisadores da língua portuguesa detectar a existência de alguns fatos linguísticos no período em questão, que dão indícios de como era a língua falada, documentada em registros escritos. Abaixo exemplificam a afirmação os verbetes pílula e sobrancelhas.

pílula $s . f$.

variantes: pilula, pílola, pirola.

Pequena bolinha composta por diversas substâncias medicamentosas, para ser engolida mais facilmente.

Deftas pilulas deve tomar o enfermo pela manhã em jejum hum efcropulo, que faõ doze vintens de pezo, e deve continuallas até fe acabarem, ou de todo eftar faõ; que pela experiencia, que dellas tenho, infiro, querendo Deos, fique livre: [...]. JOSÉ ANTONIO MENDES (1770) [1770], CAPITULO XII - DAS OBSTRUCSOENS [A00_2402 p. 78].

Jalapa. [...] Só se usa da sua raiz ou cortada em piquenas talhadas, e lançadas de infusão em água ardente; e depois separada a água ardente se ministra aos doentes; ou mais ordinariamente da sua raiz [roto o original] [co]mo outros lhe chamam extracto tomado em pílolas. PE. JOÃO DANIEL (1976) [1757], PARTE TERCEIRA - DÁ NOTICIA DA SUA MUITA RIQUEZA NAS SUAS MINAS NOS SEUS MUITOS, E PRECIOSOS HAVERES, E NA MUITA FERTILIDADE DAS SUAS MARGENS - TRATADO QUINTO - DO PRINCIPAL TESOURO DO RIO AMAZONAS - CAP. $4^{\circ}$ - PROSEGUE-SE A NOTÍCIA DOS MAIS PRECIOSOS HAVERES DO AMAZONAS ETC. [A00_1871 p. 406].

\section{$1^{\text {a }}$. datação [1626]}

Se acaso me não tem vindo successor mandaime a encommenda de ferramenta que vos mandei pedir e juntamente uma pouca de massa de pirolas de gera de galeno, com a receita, E materiaes de que se fazem para que eu cá as componha porque são muito boas para os olhos [...]. FR 
CHRISTOVÃO DE LISBOA (1906) [1626], VII. - DIVERSOS DOCUMENTOS SOBRE O MARANHÃO E O PARÁ: 15. TRÊS CARTAS DE FR. CHRISTOVÃO DE LISBOA (2 DE OUTUBRO DE 1626, 2 E 20 DE JANEIRO DE 1627) [A00_0591 p. 410].

A tão usual pirola da linguagem falada já está documentada em 1626'

sobrancelha $s . f$.

variantes: sobrancêlha, sombrancelha.

Os cabelos que ficam na parte inferior da testa, acima das arcadas dos olhos.

BAIACU DE ESPINHO. [...] Tegumento huma cutis tensa, grossa, presemeada de grandes, e agudissimos espinhos hum pouco aduncos, de materia ossea durissima; junto as sobrancêlhas dous maiores, em forma de cornas, e no meio da fronte outro menor na mesma direcção. FRANCISCO ANTÔNIO DE SAMPAIO (1971) [1782], BAIACÚ DE ESPINHO [A00_1782 p. 65].

[...] todos moços bem feitos, [...] as sombrancelhas rapadas tôdas em geral, as barbas crescidas úas mais, outras menos, e perguntando-lhes porque as não rapavam, ou traziam como nós, responderam por acenos, que por não terem com quê. AFONSO BOTELHO DE S. PAIO E SOUSA (1962) [1771], RELAÇÃO DO PRIMEIRO ENCONTRO QUE TIVEMOS COM OS ÍNDIOS DO SERTÃO DO TIBAGI, NOS CAMPOS DE GUARAPUAVA, AOS 16, E AOS 17 DE DEZEMBRO DE 1771 [A00_2297 p. 220].

Também a unidade sombrancelha tem registro mais antigo que sobrancelha.

Alguns aspectos da morfologia do português podem ser encontrados na busca das variantes. A entrada ouvidoria que apresenta 6 variantes, a saber: ovedoria, uvedoria, ovidoria, ouuedoria, ouuidoria, ouvedoria, documenta não só a instabilidade da grafia na época, mas também fenômenos como a redução do ditongo. Destacam-se os contextos de ovedoria e ovidoria.

[...] que nelle forem entruduzidos para o donativo do dote de Ingalaterra e pas de OLanda, e as desta Comarca foi tambem premitido por provisão do Primeiro de Setembro de 1699; quando se creou esta Ovedoria. RAPHAEL PIRES PARDINHO (OUVIDOR) MANOEL DE MIRANDA FREIRE (ESCRIVÃO) (1921) [1721], AUTOS DE PROVIMENTOS DE CORREIÇÕES [M00_0002 p. 19].

[...] deque morreo muita gente, principal mente Velhos, eCrianças; adurou thé oSeguinte anno. Foi no mes de Outubro deste mesmo anno extinta aoVidoria desta Villa, effeito Ouvidor em Villa Bella o Doutor Juis de Fora della Manoel Fanqueiro Frausto [...]. . JOZÉ BARBOZA DE SÁ (ADVOGADO DA VILA DE CUIABÁ), ANGELO DOS SANTOS (SECRETÁRIO DO GOVERNO), MIGUEL JOZÉ RODRIGUES (ESCRIVÃO DA CÂMERA). [1782], ANAES DO SENADO / ATAS DE CUIABÁ [M00_0058 fol. 54].

O fato contrário também foi detectado, ou seja, unidades do léxico são ditongadas, como em:

$\operatorname{cereja}^{1} s . f$.

variante: cereija.

Fruto da cerejeira, de tamanho pequeno, pele vermelha e fina.

[...] a qual assim madura te a cutis liza, e tenue que cobre huma delgada polpa de sabor 
adstringente, depois da qual se acha huma semente dura igual á da cereija. FRANCISCO ANTÔNIO DE SAMPAIO (1971) [1782], PAO POMBA [A00_1646 p. 32].

No que tange à tipologia da definição, adotou-se a proposta de Bosque (1982), que estabelece uma taxonomia da definição de acordo com: a) a natureza da metalinguagem empregada na definição; b) a natureza do definido e a informação proporcionada na definição; c) a modalidade da definição: científica, literária, humorística; d) a estrutura sintática da definição: aditivas, disjuntivas, etc.

De acordo com a natureza da metalinguagem empregada, as definições dividem-se em próprias e impróprias ou metalinguísticas. Nas definições próprias, busca o redator mostrar o que significa a palavra na fala, e em contextos determinados, pois é consenso que os dicionários devem registrar os sentidos consolidados pelo uso. Ao contrário, as definições impróprias não são verdadeiras definições, mas explicações que indicam como e para que se emprega a palavraentrada ou lema. É o tipo de definição possível para as palavras gramaticais. São, portanto, as definições próprias, baseadas na metalinguagem empregada, que maior número de possibilidades definicionais oferecem ao redator. Nesta classificação se incluem:

1) as definições hiperonímicas, também chamadas de inclusivas, aristotélicas, de gênero próximo + diferença específica, são aquelas em que a unidade léxica é remetida a uma categoria maior de extensão semântica, o hiperônimo ou incluinte, e onde a unidade é seu subordinado ou hipônimo;

2) definições sinonímicas, aquelas que são compostas por uma ou mais palavras, separadas por vírgulas, e pertencentes a mesma classe gramatical do lema. Muito embora este tipo de definição possa trazer equívocos em virtude do círculo vicioso que pode causar, é aconselhável seu emprego, principalmente quando a classe gramatical do definido é um adjetivo ou um verbo;

3) definições antonímicas, compreendem as chamadas inclusivas negativas, nas quais há uma negação semântica (imobilidade $=$ falta de mobilidade), e as exclusivas, que consistem em definir a palavra negando o seu oposto (cru/ não cozido).

De acordo com a natureza do definido e a informação proporcionada na definição, Bosque (1982) estabelece dois tipos de classificação:

1) definições enciclopédicas ou reais e definições lexicográficas, nominais. As enciclopédicas descrevem os objetos e as lexicográficas definem palavras. Acrescente-se a este tipo de definição a chamada definição ostensiva, ao lado da enciclopédica, que remete ao objeto que possui a propriedade que se define. Este tipo de definição aplica-se às cores.

2) definições explicativas que delimitam o conceito ou refletem a essência de uma determinada categoria que o falante pode identificar ou conhecer, mas não sabe definir, ou definições construtivas próprias dos tecnicismos e das unidades léxicas formadas por siglas.

Da taxonomia apresentada por Bosque, são de interesse neste artigo as duas primeiras, ou seja, a natureza da metalinguagem empregada e a natureza do definido, com vistas às definições da nomenclatura do DHPB.

Na elaboração de definições hiperonímicas ou de gênero próximo + a diferença específica, buscou-se, muitas vezes o contexto para se estabelecer a diferença especifica em se tratando de referentes da flora, fauna, ou ainda, de objetos e utensílios.

Muitos dos documentos que integram o banco de dados são relatos de viagens de jesuítas ou de portugueses designados por Portugal para conhecer e depois relatar a natureza brasileira, em especial a flora e fauna. Assim, a descrição das plantas, flores e frutos, ou ainda dos animais, realçam as particularidades de cada elemento que pode servir de diferença específica numa definição, já que não é empregada nenhuma terminologia científica nas definições, exceto, como já mencionado anteriormente, quando termos científicos estão no banco de dados e permitem que se faça remissivas. 
Eirara - Este animal se parece com gato de Algalia: ainda que alguns dizem que o não he, são de muitas côres, sc. pardos pretos, e brancos: não comem mais que mel [...[. PADRE FERNÃO CARDIM (1980) [1585], I - DO CLIMA E TERRA DO BRASIL - E DE ALGUMAS COUSAS NOTAVEIS QUE SE ACHÃO ASSI NA TERRA COMO O MAR. [A00_0749 p. 27].

Jaboticaba - Nesta arvore se dá huma fructa do tamanho de hum limão de seitil; a casca, e gosto, parece de uva ferral, desde a raiz da arvore por todo o tronco até o derradeiro raminho; he fructa rara, e acha-se sómente pelo sertão a dentro da capitania de São Vicente. PADRE FERNÃO CARDIM (1980) [1585], I - DO CLIMA E TERRA DO BRASIL - E DE ALGUMAS COUSAS NOTAVEIS QUE SE ACHÃO ASSI NA TERRA COMO O MAR. [A00_0749 p. 37].

Os contextos acima extraídos dos relatos do Pe. Fernão Cardim (1548-1549? - 1625) auxiliaram o redator na construção dos verbetes. Quase todos os relatos usam da comparação com outros referentes conhecidos do autor, com o objetivo de melhor mostrar a realidade brasileira ao rei de Portugal.

Com relação à definição da flora, quando foi possível, evidenciaram-se as propriedades ou virtudes curativas de algumas plantas. Veja-se o exemplo abaixo:

almeirão $s . m$.

variante: almeiraõ.

Planta hortense, amargosa, utilizada na culinária e para fins medicinais como estomático.

Toda a hortalice daria, si chegasse a sua semente a nascer; tambem já se cultivou almeirão, e se deu grandioso em uma horta, que teve o capitão Bento Joseph do Rego. ALEXANDRE RODRIGUES FERREIRA [séc. XVIII], 2. ${ }^{a}$ PARTE: BAIXO RIO NEGRO - SUPPLEMENTO A' PARTICIPAÇÃO GERAL DO RIO NEGRO. [A00_2244 p. 735].

A diéta deve fer franga, frango, gallinha, perdiz, cozido tudo, e fe lhe ajuntará, na panella folhas, e raizes de chicoria, ou de almeiraõ, e tambem alguns graõs de bico [...]. JOSÉ ANTONIO MENDES (1770) [1770], CAPITULO XII - DAS OBSTRUCSOENS [A00_2402 p. 80].

\section{1. a datação [1585]}

Outras ervas ha que tambem servem para medicinas, como são serralhas, beldroegas, bredos, almeirões, avencas, e de tudo ha grande abundancia, ainda que não têm estas ervas a perfeição das de Espanha [...]. PADRE FERNÃO CARDIM (1980) [1585], I - DO CLIMA E TERRA DO BRASIL - E DE ALGUMAS COUSAS NOTAVEIS QUE SE ACHÃO ASSI NA TERRA COMO O MAR [A00_0749 p. 44].

quina $^{2}$ s.f.

Denominação comum a árvores e arbustos sul-americanos, de casca amarga, rica em quinino, com propriedades tônicas, adstringentes e que combate a febre.

Não é o meu intento descrever aqui as muitas, e grandes riquezas, que produzem espontaneamente as matas do Amazonas como são os cravos, as salsas, canela, quina quina, baunilhas, bálsamos, cacaos, e muitas outras que abundam [...]. PADRE JOÃO DANIEL (1976) [1757], PARTE QUINTA - EM QUE MOSTRA UM NOVO, E FÁCIL MÉTODO DA SUA AGRICULTURA: O MEIO MAIS ÚTIL PARA EXTRAIR AS SUAS RIQUEZAS, E O MODO MAIS BREVE PARA DESFRUTAR OS SEUS HAVERES PARA MAIS BREVE, E MAIS FACILMENTE SE EFEITUAR A SUA POVOAÇÃO E COMÉRCIO - TRATADO $3^{\circ}$ DAS ESPECIARIAS, E RIQUEZAS QUE PRODUZEM NAS SUAS MATAS O AMAZONAS 
- CAP. $1^{\circ}$ - DO MEIO DE EXTRAIR AS RIQUEZAS DO SERTÃO OU MATAS DO AMAZONAS [A00_1914 p. 165].

Continuando a construção do verbete do DHPB, tão importante quanto a definição são os exemplos. Para Matoré (1968), os exemplos devem ser buscados antes da definição; eles figuram não somente para ilustrar; eles constituem a origem, a base e é sobre o exemplo que se assenta a definição lexicográfica. Isso mostra a sua importância. Tal pensamento está presente em todas as definições do DHPB. Pode-se afirmar que os exemplos são autênticos e abonados, adquirindo, assim, o estatuto de enunciado, pois trazem consigo fatos históricos que exigem que o lexicógrafo busque o contexto maior onde o enunciado está inserido. Um exemplo bastante representativo é o da construção do verbete contagem. Dos valores polissêmicos encontrados nas ocorrências da unidade lexical no banco de dados, uma delas só foi possível ser entendida, pesquisando no contexto da história colonial brasileira. A definição de contagem no contexto abaixo deve ser entendida como "posto de fiscalização e arrecadação especializado na cobrança dos tributos incidentes sobre animais e outras mercadorias em trânsito de uma capitania para outra".

Da mesma sorte, devem protestar os mesmos vassalos que em nenhum tempo se poderá lançar imposto aos gêneros da terra produzidos dentro das atuais demarcações das contagens, e que caso suceda moverem-se circunstâncias que obriguem a mudar alguma das contagens para lugar mais contíguo ao centro das Minas [...]. CAETANO DA COSTA MATOSO (1999) [1751], 62 [PARECER CONTRA A CAPITAÇÃO E AS CASAS DE FUNDIÇÃO E PELA IMPOSIÇÃO... [A00_0978 p. 557].

Ainda na recuperação da história na construção dos verbetes, registra-se o verbete descimento em sua variante decimento que nas 180 ocorrências, incluindo no total a variante e as formas flexionadas, tem o significado de "expedição, no período colonial, para arrebanhar índios no interior do Brasil, a fim de escravizá-los", como documentam os contextos abaixo, de anos diferentes: um do Pe. Vieira e outro de Francisco Xavier de Mendonça Furtado (1700 1769), irmão do Marquês de Pombal.

O Padre Mateus Delgado ficou com ordem de assistir as três aldeias, a que se tinha assentado viessem os índios do descimento, e fazer toda a diligência para levantar casas e recolher mantimentos com que começar a sustentar-se. ANTÓNIO VIEIRA (1925) [1654], CARTA LXV - AO PADRE PROVINCIAL DO BRASIL 1654 [A00_0157 p. 264].

[...] e que os padres só tratariam do espiritual, e patuando as mais condições que constam da instrução junta, que levou o Capitão que foi fazer êste decimento, aceitou o contrato e logo mandei para cima das cachoeiras uma escolta de soldados, [...] FRANCISCO XAVIER DE MENDONÇA FURTADO (1963) [1755], 108. ${ }^{a}$ CARTA A SEBASTIÃO JOSÉ, NA QUAL TRATA DO MELINDROSO PROBLEMA DO DESCIMENTO DOS ÍNDIOS PARA AS ALDEIAS, A CARGO DAS DIVERSAS RELIGIÕES, BEM COMO DA CONDUTA DOS PRINCIPAIS DAS TRIBOS. MARIUÁ, 8 DE JULHO DE 1755 [A00_0361 p. 733].

Os exemplos, na construção dos verbetes, segundo Garriga Escribano (2003, p. 122) citando Luis Fernando Lara, cumprem, portanto, algumas funções importantes, pois, além de dar o contorno sintático do lema em questão, reintroduzir o vocábulo ao uso do qual foi retirado, serve de veículo para a transmissão de informações sociais e culturais. Corroborando a afirmação de Garriga Escribano, Dubois \& Dubois (1971) afirmam que os aspectos gramaticais estão presentes nos adjetivos, verbos e advérbios, enquanto que os culturais e sociais estão predominantemente presentes nos substantivos. Neste último aspecto, ressalta-se a importância do DHPB para recuperar a história.

Obedecendo a seqüência das informações conforme modelo de verbete do DHPB, compõem 
também o artigo lexicográfico a chamada marca de transição semântica, identificada como figurado. De cada lema, quando é o caso, identificam-se as metáforas e metonímias nos contextos com a respectiva definição. Neste registro, reside uma grande contribuição do DHPB para o estudo dos sentidos figurados que a unidade léxica pode adquirir nos diversos contextos de diferentes autores e épocas. Alguns exemplos ilustram a afirmação. São os sermões do Pe. Vieira um rico material para se encontrar empregos figurados das unidades léxicas.

nuvem s.f.

fig.

Envoltório, invólucro.

Tanto que o divino Sol de Justiça, Christo, se vestiu da nuvem branca de nossa humanidade, tanto que tomou carne o Filho de Deus nas entranhas purissimas da Virgem Maria [...]. PADRE ANTONIO VIEIRA (1951) [1653], 1. ${ }^{\circ}$ SERMÃO DA VISITAÇÃO DE NOSSA SENHORA: [A00_1065 p. 329].

peçonhento adj.

fig.

Que se mostra perverso; pérfido.

Consentiu Eva na mentira peçonhenta: de Eva passou a Adão, de Adão ao genero humano. PADRE ANTONIO VIEIRA (1951) [1654], 2. ${ }^{\circ}$ SERMÃO DA QUINTA DOMINGA DA QUARESMA [A00_0900 p. 165].

pomba $s . f$.

fig.

Espírito Santo.

E como esta na graça tanto brilha, No cristal de tão pura claridade A segunda Pessoa humanidade Pela culpa de Adão tomar se humilha Para que foi aceita a tal Menina? Para emblema do Amor, obra piedosa Do Padre, Filho, e Pomba essência trina: [...]. GREGÓRIO DE MATOS GUERRA (1992) [séc. XVII], CRÔNICA DO VIVER BAIANO SEISCENTISTA / II - OS HOMENS BONS / 1 - PESSOAS MUITO PRINCIPAIS / A CONCEYÇÃO IMMACULADA DE MARIA SANTISSIMA. [A00_1016 p. 81].

O artigo lexicográfico no DHPB tem registradas as unidades fraseológicas que podem ser extraídas do banco de dados também por motor de busca, mas, neste caso, não unidades simples, mas sintagmas expandidos. Sob o rótulo de locução e expressão sintagmática são registradas as unidades fraseológicas que têm o lema como unidade central.

Sobre as primeiras, busca-se registrar as locuções conjuntivas, prepositivas e adverbais. Para cada locução são registrados o significado e o contexto onde está inserida. São exemplos de locuções:

\section{Por acidente}

Dependentemente das circunstâncias e não da natureza de um ser.

Onde fem montar, nem defcahir, bordejou quinze dias; perdeu hum navio o leme; \& defarvoráraõ dous, chocando ambos por accidente, ou por defcudo. FRANCISCO DE BRITO FREYRE (1655) [1655], SENHOR [A00_2496 p. 39].

\section{De mistura}

Ao mesmo tempo; conjuntamente, simultaneamente.

Costumam os Portuguezes, imitando o costume dos indios, seccarem esta pimenta, e depois de estar bem secca a pizam de mistura com o sal, ao que chamam juquiray, em a qual molham o 
peixe e a carne, e entre os brancos se traz no saleiro, e não descontenta a ninguem. GABRIEL SOARES DE SOUSA (1938) [1587], DA AGRICULTURA DA BAHIA - (PARTE SEGUNDA - TITULO 4) [A00_0180 p. 204].

\section{Em estátua}

Em imagens de papelão ou em manequins de palha e estopa (no auto-de-fé da Inqusição).

A ousadia dos Pernambucanos servio muito a desgraça de Jeronymo de Mendoça, porque pouco tempo depois de chegado a Corte, foy posto em huma aspera prizaõ, por indicios de cumplice na traiçaõ de seu irmaõ Francisco de Mendoça Furtado, Alcaide môr de Mouraõ, que fugio para Castella, e foy degollado em estatua [...]. SEBASTIÃO DA ROCHA PITTA (1878) [1730], LIVRO SEXTO [A00_0572 p. 258].

Sem cerimônia

Familiarmente, à vontade.

[...] e por isso bom hé que VM.cê mesmo vá recebendo do que for meu athé aonde poder ser, e sem serimonia, nem cumprimentos. INÁCIO JOZÉ DE ALVARENGA (1960) [1779], 03. CARTA A JOÃO ROIZ DE MACEDO (28 DE MAIO DE 1779) [A00_1320 p. 60].

\section{Em pelo}

Sem arreio (diz-se de montaria).

Quatro mil cavalos em pêlo sem serem montados de pessoa alguma vinham adiante em um só corpo montuoso. PEDRO TAQUES DE ALMEIDA PAES LEME (1980) [séc. XVIII], RENDONS [A00_0076 p. 258].

As expressões sintagmáticas, na sequência dos fraseologismos, registram o sintagma nominal e verbal simples e o expandido, como em:

\section{Acidentes do sacramento}

A cor, o cheiro, o sabor de pão e vinho depois da consagração. [...] onde o Soberano Senhor encoberto nos accidentes do Sacramento como verdadeiro Deos com reverente culto ferá Euchariftico venerado, e nos dias defta folemnidade havia fer adorado [...]. SIMÃO FERREIRA MACHADO (1967) [1784], NARRAÇÃO DE TODA ORDEM, MAGNIFICO APPARATO DA SOLEMNE TRASLADAÇÃO DO EUCHARISTICO SACRAMENTO DA IGREJA DA SENHORA DO ROSARIO PARA HUM NOVO TEMPLO DE NOSSA SENHORA DO PILLAR MATRIS, E PROPRIA MORADA DO DIVINO SACRAMENTO EM VILLA RICA, CORTE DA CAPITANIA DAS MINAS. AOS 24 DE MAYO DE 1733 [B00_0020 p. 90].

\section{Corpo de delito}

Fato material em que se baseia a prova de um crime.

[...] e que a elle ajuntasse os mesmos officios e mais papeis que com elles se achavão incorporados, e havião servir de Corpo de dellito para por elle proceder á ditta Devassa, [...]. desconhecido (1941) [1794], DEVASSA ORDENADA PELO VICE-REI CONDE DE RESENDE - 1794 [A00_2246 p. 249].

\section{Dourar a pílula}

Apresentar, sob aspecto favorável, algo desagradável.

e versado em alguns lugares da Sagrada Escriptura, com os quaes entendidos a seu modo dourava as pirolas, e encobria o veneno aos que o ouvião, e vião morder algumas vezes na autoridade do Summo Pontifice, no uso dos Sacramentos, no valor das Indulgencias, e em a veneração das Imagens. FREI VICENTE DE SALVADOR (1888) [1627], LIVRO TERCEIRO - DA HISTORIA DO BRASIL DO TEMPO QUE O GOVERNOU THOMÉ DE SOUZA ATHÉ A VINDA DO GOVERNADOR MANOEL TELLES BARRETO - CAPITULO DECIMO SEGUNDO - DE COMO O GOVERNADOR MEN DE SÁ TORNOU AO RIO DE 
JANEIRO, E FUNDOU NELLE A CIDADE DE S. SEBASTIÃO, E DO MAIS QUE LÁ FEZ ATHE TORNAR Á BAHIA [A00_2022 p. 80].

\section{Carregar em receita}

Anotar por escrito, registrar uma quantia recebida.

E o quinto dos escravos e mais despojos entregei na Capitania do para e fis carregar tudo en Reseita ao almox.e fr.co madr.a [...]. LUIZ ARANHA DE VASCONCELLOS (1906) [1625], VII. - DIVERSOS DOCUMENTOS SOBRE O MARANHÃO E O PARÁ: 14. INFORMAÇÃO DE LUIZ ARANHA DE VASCONCELLOS SOBRE O DESCOBRIMENTO DO RIO DAS AMAZONAS. 1625. [A00_0590 p. 393].

\section{Pagar o pato}

Sofrer as conseqüências de algo; ser vítima; pagar pelo que não fez.

[...] sempre os inimigos encontram algumas com gente, especialmente mulheres, e meninos, que não podem fugir, e não só ficam prisioneiros, mas ordinariamente pagam o pato, porque ficam objecto da ira, e vingança dos inimigos. PE. JOÃO DANIEL (1976) [1757], PARTE SEGUNDA - CAP. $9^{\circ}$ - DAS GUERRAS DOS ÍNDIOS DO RIO AMAZONAS [A00_1840 p. 235].

Toda a fraseologia documentada nos verbetes do DHPB tem por objetivo registrar que muitas expressões e locuções já eram empregadas no período que abrange o DHPB. Registrar esses fraseologismos é resgatar não só a memória linguística como a histórica.

Uma última informação completa o verbete do DHPB: a datação. Este tipo de informação é de suma importância num dicionário histórico, pois situa no tempo a presença do lema num conjunto de documentos. Faz-se, entretanto, uma ressalva: a datação que fecha o verbete do DHPB, não indica quando a palavra apareceu pela primeira vez na língua portuguesa, mas em que documento mais antigo ela está registrada. Em cada contexto estão registradas duas datas: a $1^{\mathrm{a}}$ entre parênteses indica a data da edição utilizada e a $2^{\mathrm{a}}$, em negrito e entre colchetes, indica a data em que a obra foi produzida e é esta a indicada como mais antiga. Assim, no conjunto de documentos é a Carta de Pero Vaz de Caminha que inicia a datação. Novamente, o sistema Philologic permite a localização do documento mais antigo, pois de cada ocorrência os contextos estão em ordem cronológica, do mais antigo ao mais recente. Como diz Matoré: "as palavras não caem do céu, elas aparecem em sua hora., e a data de seu nascimento (que os lingüistas chamam uma datação) é interessante na medida em que ela revela uma modificação ocorrida na história de civilização". (MATORÉ, 1928, p. 23-24). ${ }^{3}$ (trad. nossa)

A afirmação do lexicólogo francês vem ao encontro dos objetivos do DHPB e ratifica o procedimento adotado. Começando com a Carta de Caminha, tem-se o contexto abaixo:

[...] e aly amdamos todo aquele dia em calma avista delas obra de tres ou quatro legoas. e domingo xxij do dito mes aas $\mathrm{x}$ oras pouco mais ou menos ouuemos vista dasjlhas do cabo verde. s. dajlha de sã njcolaao [...]. PERO VAZ DE CAMINHA (1964) [1500], CARTA DE PERO VAZ DE CAMINHA [A00_0335 fol. 1].

No contexto acima, destacam-se jlha e amdamos, com grafia transcrita do manuscrito de Caminha. Desta forma, ao construir o verbete ilha, há que se documentar que a variante jlha está datada de 1500, ou seja, o verbete ilha terá como datação mais antiga o ano de 1500 em sua variante.

Um pouco mais complexo é o registro da datação dos verbos já que há uma variação muito

\footnotetext{
3 Les mots ne tombent pas du ciel, ils apparaissent à leur heure, et la date de leur naissance (que les linguistes appellent une datação) est intéressante dans la mesure où elle révèle une modification survenue dans l'histoire d'une civilization. (MATORE, 1968 , p. 23-24)
} 
grande nas conjugações. Assim, no contexto anterior, encontra-se amdamos e, em outros, encontra-se andamos. Na busca de uma solução, que não é a ideal, mas que permite documentar a datação do verbo, optou-se por registrar a data apenas da forma de infinitivo. Pelo processo de busca por similaridade, localiza-se a forma de infinitivo e a data mais antiga para ela.

Parece-me que nom podemos deixar de dar a roupa que trouxemos a estes que querem ser christãos, repartindo-lha até ficarmos todos iguaes com elles, ao menos, por nom escandalizar aos meus Irmãos de Coimbra, [...]. P. MANUEL DA NÓBREGA (1956) [1549], CARTA DO P. MANUEL DA NÓBREGA AO P. SIMÃO RODRIGUES, BAÍA [10? DE ABRIL] 1549 [A00_0001 p. 113].

[...] que lhe elle dise que lhe pesaua diso querelo deyxar em tal tempo e que o almyrante lhe avya de pesar diso / e que emtemdese elle comfesamte nas cousas da Repubrica e que se nom emtremetese nas cousas da Relegião [...]. JOAO DE BOLÉS (1904) [1560], PROCESSO DE JOÃO DE BOLÉS E JUSTIFICAÇÃO REQUERIDA PELO MESMO (1560 - 1564) [A00_0827 p. 273].

[...] e a outra q. tanbem pertendo dar sastifação da minha peçoa, porq. se deichar a despozicão de hum cacheiro não comvem; porq. elles fogem quando lhe parecem $\mathrm{p}^{\mathrm{a}}$ os corais e se pação $\mathrm{p}^{\mathrm{a}}$ a Bahia e os q. vivem nesta terra fazem grandes gastos com a sua peçoa [...]. FRAN. ${ }^{\text {co }}$ CRUZ (1973) [1725], CARTAS REMETIDAS PARA LISBOA-MINAS GERAIS [A00_0433 p. 257].

A dificuldade em se chegar a uma solução próxima da ideal está também no fato de que o banco de dados reúne edições de épocas diferentes, tornando, muitas vezes, incoerente o registro, como acontece nos contextos registrados, onde a forma deixar está em texto do Pe. Manuel da Nóbrega e data de 1549, em ortografia atual. Já no processo de João de Boles, de 1560 e a carta de Francisco da Cruz, de 1725, registram deixar em grafias diferentes, talvez mais apropriadas que a do Pe. Nóbrega. Mas tal descompasso se deve ao problema das edições utilizadas. A obra completa do Pe. Manuel da Nóbrega recebeu inúmeras edições, muitas delas atuais. Entretanto, o processo de João de Boles foi transcrito e publicado uma só vez nos Anais da Biblioteca Nacional do Rio de Janeiro. Já a carta de Francisco Cruz, também manuscrita, faz parte da obra Negócios Coloniais, publicada por Luís Lisanti, em única edição de 5 volumes.

Pode-se, entretanto, encontrar o infinitivo como variante, em texto mais antigo; o verbo entender tem as variantes emtemder (1562) e emtender (1500); já a forma atual entender (1555).

Muito embora haja dificuldades para se chegar a um modelo que dê conta, satisfatoriamente, de todas as ocorrências, é possível aproveitar ao máximo o material que será oferecido pelo DHPB, quando de sua conclusão.

\section{CONCLUSÃO}

O objetivo deste artigo foi apresentar algumas das contribuições que o Dicionário Histórico do Português do Brasil - século XVI, XVII e XVIII já tem dado para os estudos históricos da língua portuguesa. Muito embora ainda não esteja concluído, alguns pontos fundamentais podem ser realçados: 1) a nomenclatura do DHPB foi organizada a partir de um banco de dados construído especificamente para ele; 2) o banco, conforme foi construído com ferramenta computacional apropriada para o seu fim, é inédito e dele muitos outros estudos sobre a língua e a história do Brasil Colônia poderão ser feitos; 3) o registro de todas as variantes do lema, acompanhado dos respectivos contextos, permite estudar a variação nos seus diversos níveis: ortográfico, morfológico, fonético-fonológico; 4) os textos que compõem o banco de dados constituirão um importante material para o estudos da sintaxe e de sua variação; 5) o resgate de 
expressões sintagmáticas e de locuções contrapõem o que era usual à época e ainda permanece, do que já entrou em desuso; 6) a possibilidade oferecida pelo banco de dados de se fazer o estudo da tipologia dos gêneros textuais; 7) o estudo do vocabulário de muitas obras que, inseridas no banco de textos em sua edição princeps, permite ao lexicógrafo construir glossários e vocabulários inéditos.

Parafraseando Matoré (1968), pode-se afirmar que em determinados momentos da história de uma sociedade aparece um novo vocabulário que registra uma nova situação política, social, econômica, isto é, uma nova atitude do homem perante o mundo. As mudanças não se operam na língua de modo brusco, e os falantes não se dão conta das mudanças que ocorrem no léxico. Este pensamento do lexicólogo francês que afirma que "o vocabulário é a expressão de uma sociedade"4 (MATORÉ, 1968, p. 23), engloba plenamente os propósitos do Dicionário Histórico do Português do Brasil - séculos XVI, XVII e XVIII, registrando não só a língua portuguesa, mas também a história de três séculos da vida colonial brasileira.

\section{BIBLIOGRAFIA}

BOSQUE, Ignacio. Sobre la teoria de la definición lexicográfica. In:__ Verba, Santiago de Compostela, n. 9, 1982. p. 105-123.

CAMPOS SOUTO, Mar.; PEREZ PASCUAL, José I.. El diccionario y otros productos lexicográficos. In:__ MEDINA GUERRA, Antonia. M. (Coord.). Lexicografía española. Madrid: Ariel, 2003. p. 53-78.

CASTILLO CARBALLO, Maria. Auxiliadora. La macroestrutura del diccionário In: MEDINA GUERRA, Antonia. M. (Coord.). Lexicografía española. Madrid: Ariel, 2003. p.79101.

DUBOIS, Jean.; DUBOIS, Claude. Introduction à la lexicographie: le dictionnaire. Paris: Librairie Larousse, 1971.

GARRIGA ESCRIBANO, Cecilia. Microestrutura del diccionário: lãs informaciones lexicográficas. In:__ MEDINA GUERRA, Antonia. M. (Coord.). Lexicografía española. Madrid: Ariel, 2003. p. 103-126.

HAENSCH, Gunther. Tipologia de las obras lexicográficas. IN: _HAENSCH, G. et al. La lexicografia: de la lingüística teórica a la lexicografia práctica. Madrid: Editorial Gredos, 1982. p.95-187.

LISANTI, Luis. Negócios Coloniais (uma correspondência comercial do século XVIII). São Paulo: Visão Editorial, 1973, 5 v.

MATORÉ, Georges. Histoire dês dictionnaires français. Paris : Librairie Larousse, 1968. MURAKAWA, Clotilde de A.Azevedo A homonímia na lexicografia portuguesa de setecentos: Bluteau e Morais. In Gramática e Humanismo- Actas do Colóquio de Homenagem a Amadeu Torres. v. 1 .Braga: Editora da Faculdade de Filosofia - Universidade Católica Portuguesa, p.541- 554, 2005.

MURAKAWA, Clotilde de A. Azevedo. António de Morais Silva: lexicógrafo da Língua Portuguesa. Araraquara: Cultura Acadêmica Editora, 2007.

PORTO DAPENA, José. Alvaro. Manual de técnica lexicográfica. Madrid: Arco/Libros, 2002. REY-DEBOVE, Josette. Léxico e Dicionário. Trad. Clóvis Barleta de Moraes. Revista Alfa, v. 28 (suplemento), São Paulo, p. 45-69, 1984.

\section{OBRAS DE REFERÊECIA}

\footnotetext{
4 “Le vocabulaire est l’expression d’une société » (MATORÉ, 1968, P. 23)
} 
BLUTEAU, Raphael. Vocabulário portuguez e latino. Coimbra: Collegio das Artes da Companhia de Jesu ${ }^{5}, 1712-1728.10 \mathrm{v}$.

SILVA, Antonio. de Morais. Diccionario da lingua portugueza. Lisboa: Officina de Simão Thaddeo Ferreira, 1789. 2 v.

SILVA, Antonio. de Morais. Diccionario da língua portugueza. Lisboa: Typographia Lacerdina, 1813. $2 \mathrm{v}$.

SILVA, Antonio. de. Morais. Diccionario da língua portugueza. 6.ed. Lisboa: Typographia de Antonio José da Rocha, 1858. 2 v.

SILVA, Antonio. de. Morais. Diccionario da língua portugueza. 9.ed.. Lisboa: Empreza Litteraria Fluminense de Santos, Vieira \& Commandita, [18-]. 2 v.

SILVA, Antonio. de Morais. Grande dicionário da língua portuguesa. 10.ed. Orgs. Augusto Moreno, Cardoso Junior e José Pedro Machado. Lisboa: Editorial Confluência, 1949-1959. 12 $\mathrm{v}$.

VIEIRA, Frei Domingos. Grande diccionario portuguez ou thesouro da lingua portugueza. Porto: Editores Ernesto Chardron e Bartholomeu H. de Moraes, 1871-1874. 5 v.

VOCABULÁRIO ortográfico da língua portuguesa. 5 ed. São Paulo: Global, 2009.

${ }^{5} \mathrm{Na}$ folha de rosto do Vocabulário está Jesu. 